Second Meeting April 13th, 1883.

John Sturgeon Mackay, Esq., M.A., F.R.S.E., President, in the Chair.

\title{
The Triangle and its Six Scribed Circles.
}

\section{By Johy Sturgeon Mackay, M.A.}

[When the Edinburgh Mathematical Society was founded, it was deemed impracticable, from the expense that would be involved, to print the papers read at its meetings. It was, bowever, resolred that copies of them should be deposited with the Secretary, and that these copies should as far as possible be made accessible to the members of the Society. Want of leisure during the first session prevented me from doing my part in carrying out this intention of the Society, and committing to writing the paper which was delivered at the second meeting. During its second session, the Society resolved to print its proceedings in whole or in abstract; and a beginning was made with the second rolume, whe first being left over for future consideration, as the cost of printing absorbed nearly the entire income of the Society.

Some time afterwards, through the exertions of the late Mr A. Y. Fraser, who was then Secretary of the Society, and whose opening career was cut short by untimely death, a sum of money was raised by voluntary subscription to defray the expense of printing Vol. I. Seeing that it was desired by others as well as by myself to have the collection of properties of the triangle as ample as possible, I obtained the consent of the Society to delay the publication of the volume. This delay has been unduly prolonged, and no one but myself is to be blamed in connection with it.

The collection, divided into twenty sections, which has resulted is a tolerably large one, filling somewhat more than 1600 quarto pages of manuscript. Owing to the impossibility of printing all this without a large expenditure of money, that portion has been selected which best corresponds with what was communicated to the Society. The six scribed circles of the title were the inscribed, the escribed, 
the circumscribed, and, as I called it then, the medioscribed (or nine point) circles. Part of the section treating of the nine point circle was printed in abstract in Vol. II. of the Proceedings, and the rest, considerably enlarged, in Vol. XI. What is bere printed consists of the first section, with the principal properties of some other sections incorporated in it, and a statement of the notation which is employed throughout all the sections. The remainder of the collection will, unless it is anticipated somewhere else, see the light gradually, I hope, in the Proceedings of the Society.

This fragmentary memoir would have appeared more original if I had left without note or comment all those properties which I had discovered for myself, and it would certainly have looked more learned if $I$ had furnished references to all the authorities who have discussed various parts of the subject. Unless there was reason to the contrary, as, for example, when a new mode of proof was given, I have noted simply the first discoverer of a theorem, and have suppressed all mention of subsequent discorerers. I have not concerned myself with problems, with questions of loci, or with trigonometrical expressions relating to the triangle, for the simple reason that I xished to keep the memoir within manageable bounds. The same reason has also led me to defer consideration of the properties of the triangle, in which other conic sections than the circle are involved.

The research which has been necessary to render the historical notes scattered throughout the whole collection worthy of attention could not, in the limited leisure at my disposal, have been undertaken except with the aid of many friends. I gladly seize the present opportunity of recording my gratitude for many favours to $m y$ colleagues of the Edinburgh Mathematical Society, Messrs Alison, Allardice, Gibson, Harvey, Macdonald, Pressland, and, in particular, the late Mr A. Y. Fraser; to Messrs Anderson, Langley, and Tucker in England; to Professor Neuberg in Belgium; to Dr Grebe and Professor Fuhrmann in Germany: and to Messrs Aubert, Lemoine, De Longchamps, D'Ocagne, and Poulain in France. For two successive summers Messrs Nony and Vuibert put a complete copy of their Journal de Mathematiques Elémentaires in my hands, with liberty to make such extracts from it as I pleased; and Mr De Longchamps, with the courtesy of his nation, has several times placed his whole library at my disposal, even when he was absent from Paris.] 